\title{
A Chemoselective and Scalable Transfer Hydrogenation of Aryl Imines by Rapid Continuous Flow Photoredox Catalysis
}

\author{
Rowan L. Pilkingtona, Nikolai P. Rossouw ${ }^{a}$, Dean J. van $\mathrm{As}^{\mathrm{a}}$, and Anastasios Polyzos ${ }^{\star a b}$
}

\begin{abstract}
The chemoselective reduction of diaryl imines in the presence of competitively reducible groups is uniquely accessed through precise control of reaction and irradiation time by continuous flow visible light photoredox catalysis. The method enables the mild and efficient transfer hydrogenation of diaryl imines in the presence of sensitive functionality including halides, ester, ketone, and cyano groups. The flow protocol is efficient, rapid (>98\% conversion within $9 \mathrm{~min}$ ) and readily scaled to deliver multigram quantities of amine products in high purity.
\end{abstract}

Keywords: Flow chemistry $\cdot$ Imines $\cdot$ Photoredox $\cdot$ Radicals $\cdot$ Transfer hydrogenation
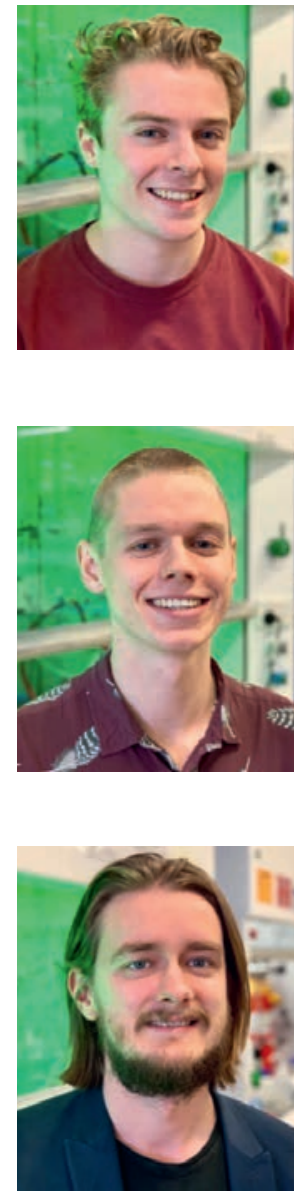

Rowan L. Pilkington was born in England before moving to Australia in later life. He studied Science (Chemistry) at the the University of Melbourne, working in his final year under the supervision of Dr. A. Polyzos on photoredox carbonylation in flow. He has completed an MSc in the same group, with research interests in the development of novel photoredox processes and their application in flow processing.

Nikolai P. Rossouw was born in Richards Bay, South Africa, before immigrating to Australia. He graduated with a BSc (Chemistry) from the University of Melbourne, working on photoredox thiolation in flow and synthesis of organic photoredox catalysts with Dr. A. Polyzos. $\mathrm{He}$ is continuing a MSc with the Polyzos laboratory developing natural product total synthesis in flow.

Dean J. van As grew up in Melbourne, Australia. He obtained an MSc from the chemistry department at the University of Melbourne in 2015 under the supervision of Dr. W. Wong. He is currently completing his $\mathrm{PhD}$ studies at the University of Melbourne under the supervision of Dr. A. Polyzos in photoredox catalysis. His areas of interest involve the development of new visible light photocatalytic methods for the synthesis and functionalization of amines in batch and flow.

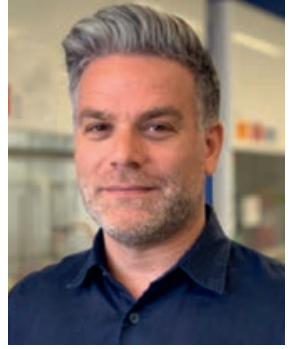

Anastasios Polyzos was awarded his $\mathrm{PhD}$ in 2005 from La Trobe University and appointed to Research Fellow at the Australian national science agency, CSIRO in the same year. In 2008 he pursued postdoctoral research at University of Cambridge under guidance of Professor Steven V. Ley FRS. In 2011 he returned to Australia to lead the flow chemistry and catalysis group at CSIRO in Australia. He established an independent research career with appointment to Senior Lecturer within the School of Chemistry, University of Melbourne in 2015. His research interests include the development of new methods and enabling technologies for organic synthesis, photocatalysis, $\mathrm{C}-\mathrm{H}$ reaction discovery, and the development of sustainable industrial process chemistry. Anastasios currently serves as Director of the Australian Research Council Industrial Transformation Training Centre for Chemical Industries.

The ubiquity of aryl amines in pharmaceutical, agrochemical and industrial products has fostered the development of methods enabling their straightforward and scalable production. ${ }^{[1]}$ Innumerous protocols for the synthesis of aryl amines exist, encompassing $\mathrm{S}_{\mathrm{N}} \mathrm{Ar}$ of aryl fluorides,[2] Ulmann, BuchwaldHartwig and Chan-Evans-Lam coupling, [3] and hydrogen borrowing. ${ }^{[4]}$ One of the most robust and well-established methods is reductive amination by heterogeneous catalytic hydrogenation of imines on platinum and palladium metal. Whilst catalytic hydrogenation is scalable and generally economically viable, chemoselectivity is challenged by the presence of multiple unsaturated bonds or other reducible groups on the intermediates and products. ${ }^{[5]}$ The development of methods for reductive amination under mild conditions with requisite chemoselectivity and functional group tolerance remains a focus in industrial, and academic laboratories. ${ }^{[6]}$ These requirements become progressively important when reductive amination is required in the late-stage functionalisation of targets with increasing complexity, including bioactive lead molecules and natural products. Mild hydride transfer agents 
Scheme 1. Continuous flow processing enabling the scalable, chemoselective photoredox transfer hydrogenation of imines. $F G$ = functional group.
Our Previous Work:<smiles>BrC(Br)=Nc1ccccc1</smiles>

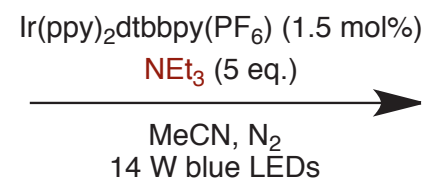<smiles>BrC(Br)Nc1ccccc1</smiles>

$14 \mathrm{~W}$ blue LEDs

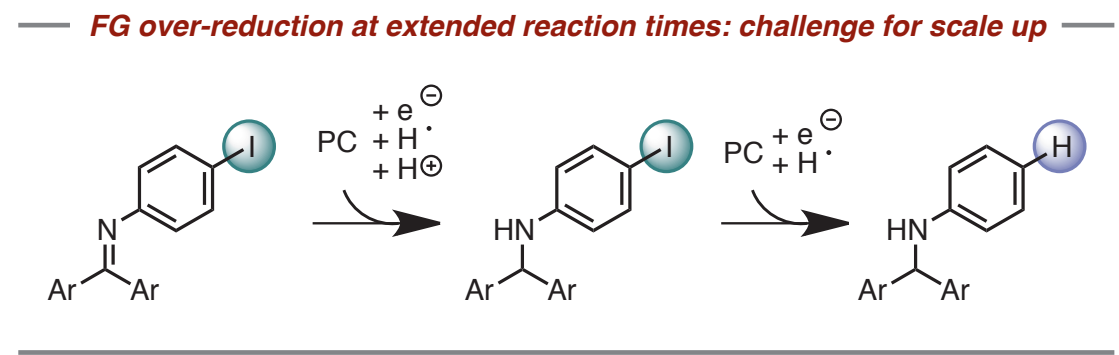

This Work:<smiles>[Li]C(Br)=Nc1ccc(-c2ccccc2)cc1</smiles>

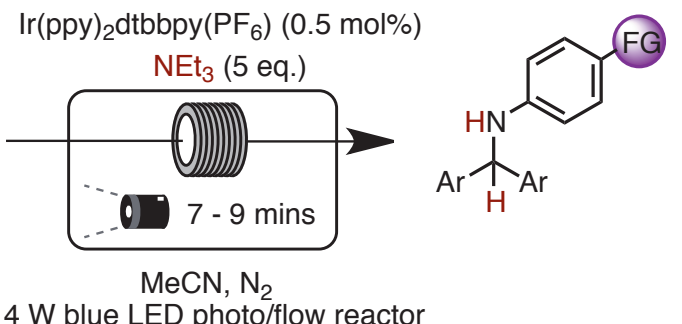

$14 \mathrm{~W}$ blue LED photo/flow reactor

including $\mathrm{NaCNBH}_{4}$ and $\mathrm{NaBH}(\mathrm{OAc})_{3}$ offer opportunities for chemoselective reduction of imines, however a dependence on acidic conditions, solvent polarity and imine electrophilicity impedes application to a broader selection of substrates. ${ }^{[7]}$ Furthermore, the requirement for stoichiometric hydride transfer reagent and the formation of cyanide by-products (in the case of $\mathrm{NaCNBH}_{4}$ ) may limit the translation of these methods beyond laboratory preparation. ${ }^{[6]}$

We recently disclosed a visible light photoredox method for the catalytic transfer hydrogenation of diaryl-ketimines (Scheme 1). ${ }^{[8]}$ The process utilises triethylamine as a highly economical single source of electron, proton and hydrogen atom. The reaction was characterised by high product yields, fast reaction times and visible light as the solitary energy source. Based on literature reports, ${ }^{[9]}$ our mechanistic hypothesis (Scheme 2) was centralised on the direct single electron reduction of the diarylketimine moiety (I) to the corresponding $\alpha$-aminyl radical anion species (II) by the photoredox catalyst, followed by subsequent protonation and hydrogen atom transfer (HAT) from triethylamine radical cation (IV) and triethylamine (III) respectively to afford the hydrogenated diaryl amine (VI).

Through the course of these investigations, we observed that imines bearing an aryl-iodo substituent underwent competitive protodehalogenation with extended reaction times. To address this limitation, we reasoned that the different rates of single electron transfer (SET) to the imine moiety relative to the aryl halide, could be exploited to furnish chemoselectivity that was dependent on reaction time. Continuous flow photochemistry methods ${ }^{[10]}$ offer the temporal and spacial resolution necessary to enable the kinetically favoured reduction of the imine whilst minimising unwanted protodehalogenation. This selectivity mode can be readily achieved by establishing a finely-tuned set of reaction conditions that impede the time-dependent over-reduction of the aryl halide and can be extended to other reducible substituents. Furthermore, improved photocatalytic activity can be expected since greater light permittivity is effected over the smaller pathlength in tubular

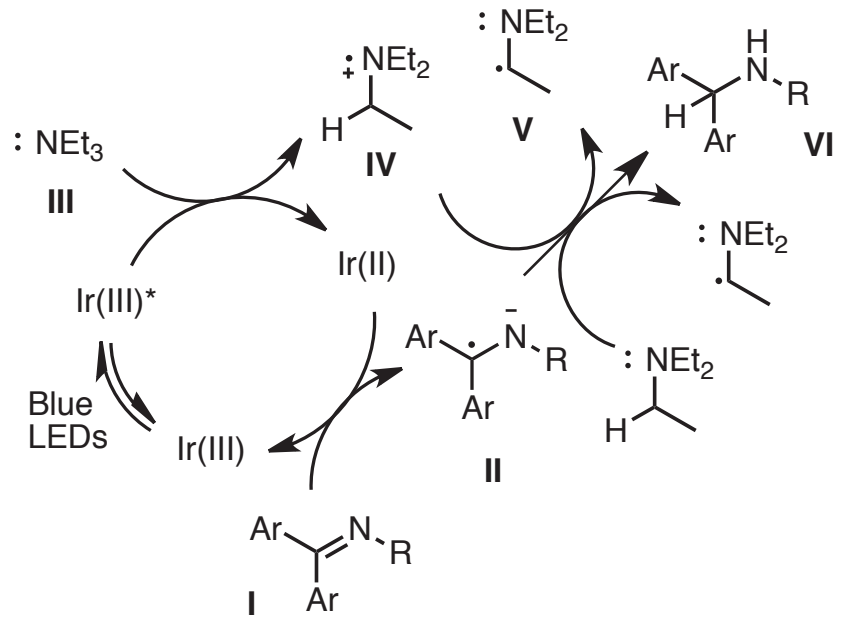

Scheme 2. Proposed mechanism of photoredox-catalysed transfer hydrogenation.

flow reactors compared to standard reaction glassware, ${ }^{[11]}$ and the continuous nature of flow chemistry could be leveraged to efficiently scale the photocatalytic chemoselective reduction. ${ }^{[12]}$

We initiated the study by assembling a flow platform consisting of a commercially available syringe pumping system (Syrris Asia) fitted with an injection port and sample loop (any commercially available system is suitable for this application). A bespoke tubular photoreactor was fitted, consisting of two 7 W $447 \mathrm{~nm}$ LED arrays and a coiled perfluoralkoxy alkane (PFA) tube ( $3 \mathrm{~mL}, 0.75 \mathrm{~mm}$ i.d.). The system was pressurised by a back pressure regulator, rated to $40 \mathrm{PSI}$ (Fig. 1) and the solvent reservoir was continually sparged with nitrogen.

The photoredox transfer hydrogenation of the aryl iodide bearing imine 1a was investigated and studies to establish conditions for the quantitative production of iodoamine $\mathbf{1 b}$ over the protodehalogenated product 1c were undertaken. Following 

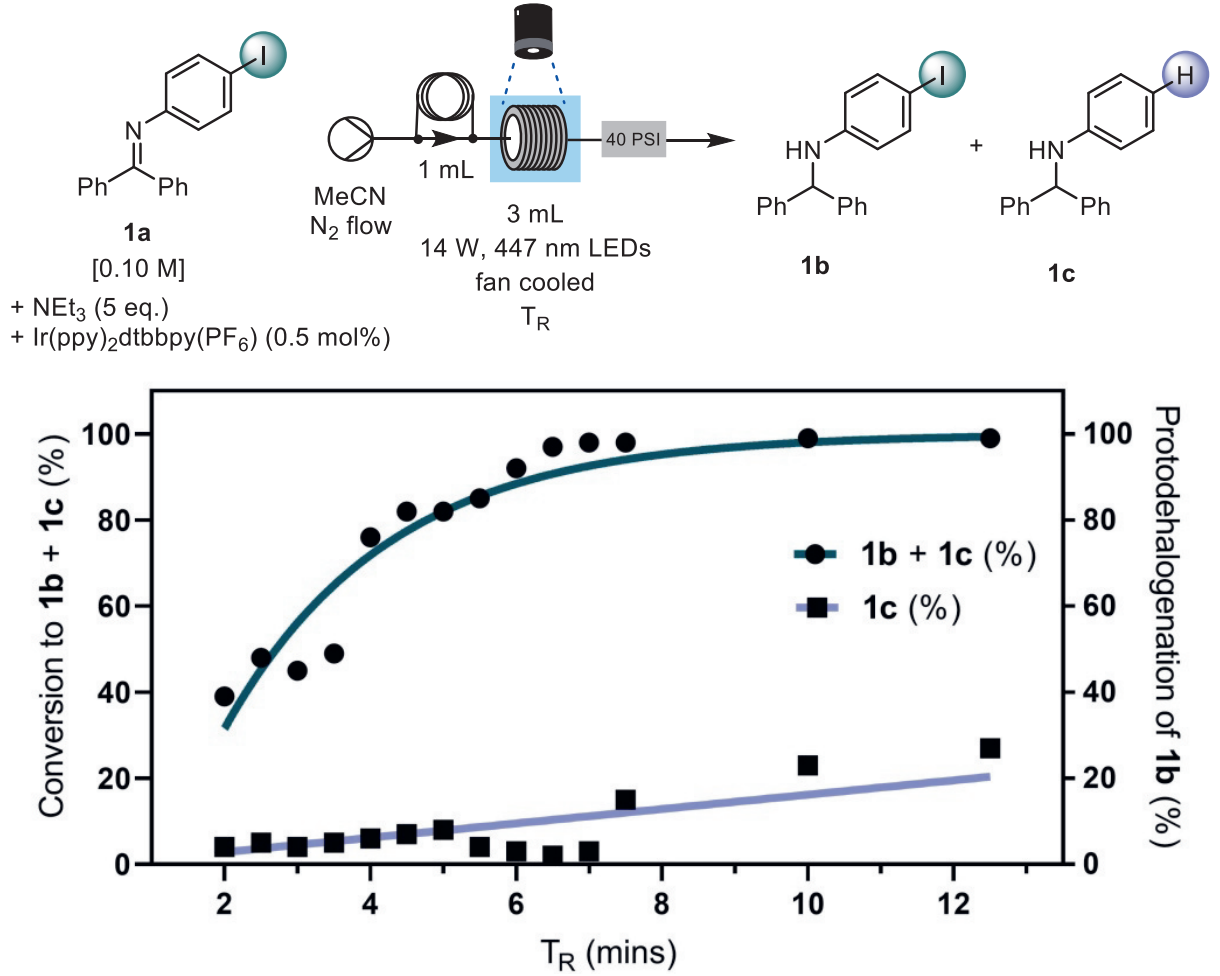

Fig. 1. Reaction time screening for substrate 1a. Conversions determined by ${ }^{1} \mathrm{H}$ NMR analysis of the crude reaction mixture. Performed on a 0.10 $\mathrm{mmol}$ scale.

optimisation of residence time (Fig. 1) excellent conversions $(>97 \%)$ of the substituted imine 1a were achieved with rapid $\mathrm{T}_{\mathrm{R}}$ as low as $7 \mathrm{~min}$. Incomplete conversion of 1a was observed at $\mathrm{T}_{\mathrm{R}}$ below $6.5 \mathrm{~min}$, indicating that the transfer hydrogenation was incomplete at faster flow rates. Slower flow rates resulting in $\mathrm{T}_{\mathrm{R}}$ more than $7 \mathrm{~min}$ increased protodeiodination of $\mathbf{1 b}$ to $\mathbf{1 c}$. Background dehalogenation by photodissociation under blue light irradiation was not detected when the photocatalyst was omitted from the reaction. With the optimised reaction time $\left(\mathrm{T}_{\mathrm{R}}=7 \mathrm{~min}\right)$ in hand, the preparation of iodoamine 1c was successfully scaled to $0.4 \mathrm{mmol}$ and isolated in $87 \%$ yield.

To demonstrate practicality and scalability of the method, we embarked on a multi-gram preparation of $\mathbf{1 b}$ (Fig. 2). The flow reactor configuration was modified to accommodate the processing of larger volumes of reagent and solvent. The sample loops were removed and the reagents were delivered from a single flask under an $\mathrm{N}_{2}$ atmosphere. FlowIR ${ }^{\mathrm{TM}}$ infra-red (FTIR) spectroscopic monitoring was utilised to monitor the reaction mixture in-line to provide real-time information on the progress of the continuous run $(9 \mathrm{~h}){ }^{[13]}$ The establishment of steady-state conditions was readily identified by in-line FTIR and the reaction product stream was collected when a steady-state was observed. The reaction front and tail (non-steady-state reaction plug) was diverted away from the collection flask to ensure unreacted material and by-products generated by dispersion effects were not collected. The desired amine 1b was isolated in 77\% (7.68

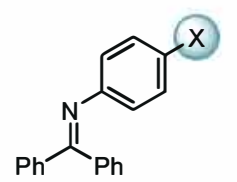

$1 \mathrm{a}(X=\mathrm{l}) 9.16 \mathrm{~g}, 23.89 \mathrm{mmol}$ or $2 \mathrm{a}(\mathrm{X}=\mathrm{Br}) 9.29 \mathrm{~g}, 27.63 \mathrm{mmol}$ $+\mathrm{NEt}_{3}(5$ eq.)

$+\operatorname{Ir}(\mathrm{ppy})_{2} \mathrm{dtbbpy}\left(\mathrm{PF}_{6}\right)(0.5 \mathrm{~mol} \%)$

Degassed MeCN [0.1 M]

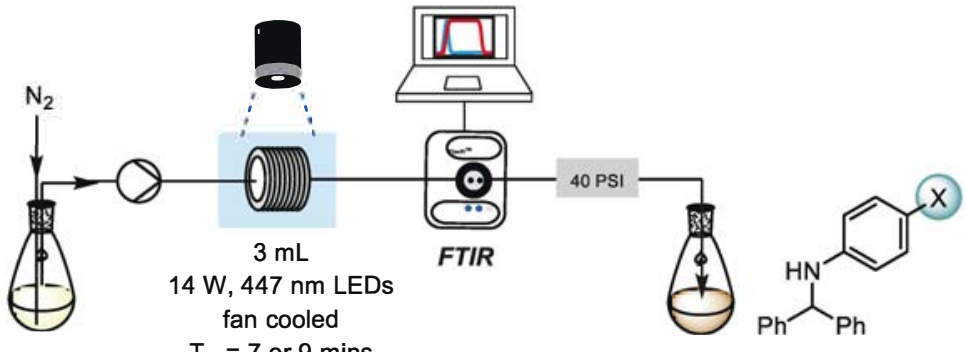

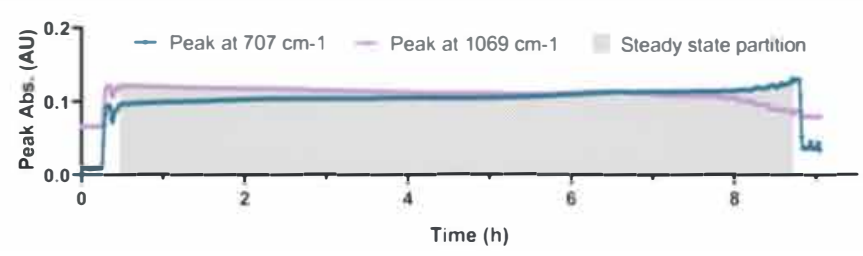

1b $(X=$ I) $77 \%(1.81 \mathrm{mmol} / \mathrm{h})$ or $\mathbf{2 b}(X=\mathrm{Br}) 79 \%(1.59 \mathrm{mmol} / \mathrm{h})$ 9 hours run-time

Fig. 2. Large-scale continuous flow photoredox transfer hydrogenation of iodo- and bromo- substituted aryl imines. In-line FTIR trace and peak absorption of diagnostic IR bands used to partition the reaction mixture at steady state (for $\mathbf{1 b}$ ). 
g) with a space-time yield (STY) of $1.81 \mathrm{mmol} / \mathrm{h}$. Parasitic protodehalogenation of $\mathbf{1 b}$ was minimised comparably to the smaller scale reaction, with $<4 \%$ conversion to $1 \mathrm{c}$ detected in the crude residue by ${ }^{1} \mathrm{H}-\mathrm{NMR}$.

We next addressed the 4-bromo substituted diphenyl aryl imine $\mathbf{2 a}$ which, according to cyclic voltammetry and unpublished experimental data, is also reducible under our photoredox system. ${ }^{[14]}$ The $T_{R}$ was extended to 9 min to effect complete transfer hydrogenation, affording $\mathbf{2 b}$ in $84 \%$ isolated yield at $0.40 \mathrm{mmol}$ scale. The bromo-substituted imine $\mathbf{2 a}$ was
In summary, a versatile flow system for the photoredox transfer hydrogenation of sensitive imines was developed, uniquely facilitating the scalable synthesis of substituted diaryl amines with time-dependent retention of functionality. Further studies are underway to implement and scale this photoredox transfer hydrogenation protocol in new multistage flow systems.

\section{Supplementary Information}

Supplementary information is available on https://www.ingentaconnect.com/content/scs/chimia
Scheme 3. Selected scope of imines with sensitive functional groups. Isolated yields are shown and reactions were performed on $0.40 \mathrm{mmol}$ scale. $\mathrm{FG}=$ functional group.<smiles>[Mg]C(Br)=Nc1ccc([Se-])cc1</smiles>

$[0.10 \mathrm{M}]$ $+\mathrm{NEt}_{3}$ (5 eq.) $+\operatorname{Ir}(\mathrm{ppy})_{2} \mathrm{dtbbpy}\left(\mathrm{PF}_{6}\right)(0.5 \mathrm{~mol} \%)$

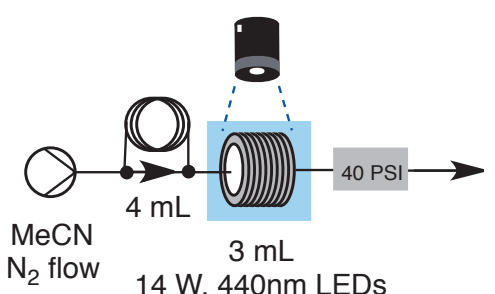

$14 \mathrm{~W}, 440 \mathrm{~nm}$ LED

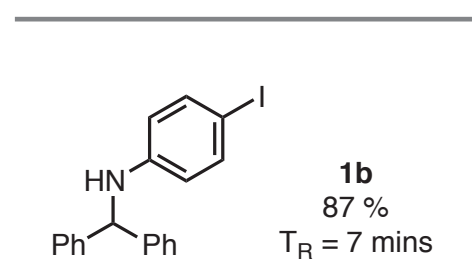<smiles>CCOC(=O)c1ccc(NC(c2ccccc2)c2ccccc2)cc1</smiles>

$98 \%$<smiles>BrC(Br)Nc1ccc(C(Br)Br)cc1</smiles>

$\mathrm{T}_{\mathrm{R}}=7$ or 9 mins<smiles>Brc1ccc(NC(c2ccccc2)c2ccccc2)cc1</smiles>

$2 b$
$84 \%$<smiles>CC(=O)c1ccc(NC(c2ccccc2)c2ccccc2)cc1</smiles><smiles>O=[N+]([O-])c1ccc(C(Nc2ccccc2)c2ccccc2)cc1</smiles>

$2 f$
$0 \%$ submitted to the scaled procedure with in-line FTIR monitoring, providing $6.44 \mathrm{~g}$ of the corresponding amine in $79 \%$ yield, with a space-time yield of $1.59 \mathrm{mmol} / \mathrm{h}$. Notably, the scaled reaction products could be isolated in high purity by simple filtration through silica and trituration with hexanes from the crude reaction mixture.

Substrates with cyano, aryl ketone and ester substituents on the diphenylimine scaffold were investigated as other potentially reducible groups under the reaction conditions (Scheme 3 ). ${ }^{[14]}$ The functional groups were well tolerated with preferential reduction of the imine and with complete conversions to the corresponding amine at $0.4 \mathrm{mmol}$ scale. A nitro-substituted imine did not afford the product $\mathbf{2 f}$ under the optimised reaction conditions, most likely due to preferential electron transfer to the electron deficient aryl ring.

To validate the effectiveness of the flow procedure, the rate of conversion and protodehalogenation of 1a was examined under batch photoredox conditions (Scheme 4A). The reduction of 1a on $1 \mathrm{mmol}$ scale proceeded as expected with $99 \%$ conversion of the starting imine effected after $3 \mathrm{~h}$ of irradiation with TLC monitoring, however $64 \%$ protodehalogenation was observed by ${ }^{1} \mathrm{H}$ NMR analysis. A traditional reduction with $\mathrm{NaBH}_{4}$ (Scheme 4B) did not effect complete conversion to $\mathbf{1 b}$ even after $24 \mathrm{~h}$. Finally, the halogenated product $\mathbf{1 b}$ prepared via the chemoselective photocatalytic reduction protocol was submitted to a representative Sonogashira coupling reaction ${ }^{[15]}$ with phenylacetylene to afford a further functionalised alkynyl product in $82 \%$ yield (Scheme 4C).

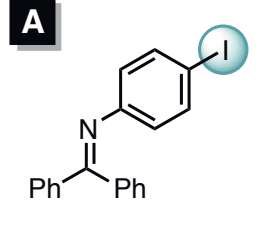

$1 a$

\section{B}<smiles>Clc1ccc(N=C(c2ccccc2)c2ccccc2)cc1</smiles>

1a

C<smiles>O=Cc1ccc(NC(c2ccccc2)c2ccccc2)cc1</smiles>

$1 \mathrm{~b}$

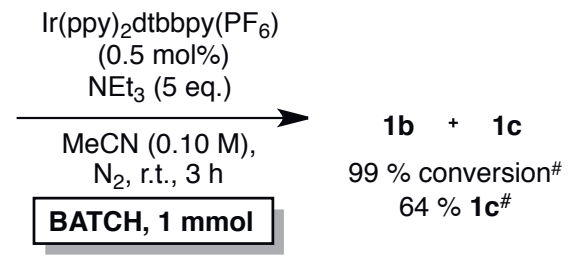

$\frac{\mathrm{NaBH}_{4} \text { (1.5 eq.) }}{\mathrm{MeOH},}$

$\mathrm{N}_{2}, 0^{\circ} \mathrm{C}$ to r.t., $24 \mathrm{~h}$

BATCH, $1 \mathrm{mmol}$

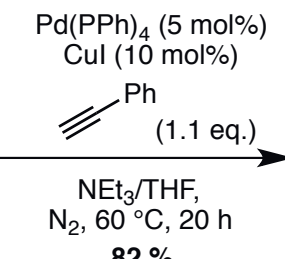

$82 \%$<smiles>C(#Cc1ccc(Nc2ccccc2)cc1)c1ccccc1</smiles>

1d
Scheme 4. A) Protodehalogenation behaviour under standardised batch photoredox conditions. Progress was monitored by TLC. B) Transfer hydrogenation of diaryl ketimine with $\mathrm{NaBH}_{4}$. C) Further transformation of the chemoselectively reduced iodo-amine. ${ }^{[16]} \#=$ Determined by ${ }^{1} \mathrm{H}$ NMR analysis of the crude reaction mixture. 


\section{Acknowledgements}

The authors acknowledge Mr Vir H. Ghandi who assisted RLP with the experimental procedures and Professor Paul Francis (Deakin University) for the kind loan of the Syrris Asia syringe pump system. DvA acknowledges the University of Melbourne, Melbourne Research Scholarship (MRS). AP acknowledges the University of Melbourne and CSIRO for the joint Establishment Grant.

Received: May 8, 2019

[1] a) E. Vitaku, D. T. Smith, J. T. Njardarson, J. Med. Chem. 2014, 57, 10257 , doi: 10.1021/jm501100b; b) M. Baumann, I. R., Baxendale, Beilstein J. Org. Chem. 2013, 9, 2265, doi:10.3762/bjoc.9.265; c) S. D., Roughley, A. M. Jordan, J. Med. Chem. 2011, 54, 3451, doi: 10.1021/jm200187y.

[2] J. March, 'Advanced Organic Chemistry: Reactions, Mechanisms, and Structure', Wiley, New York, 1992, 641

[3] a) C. Sambiago, S. P. Marsden, A. J. Blacker, P. C. McGowan, Chem Soc. Rev. 2014, 43, 3525, doi: 10.1039/C3CS60289C; b) K. Okano, H. Tokuyama, T. Fukuyama, Chem. Commun. 2015, 50, 13650, doi: 10.1039/ C4CC03895A; c) M. Carril, R. SanMartin, E. Dominguez, Chem. Soc. Rev 2008, 37, 639, doi: 10.1039/B709565C; d) J. F. Hartwig, Nature 2008, 455, 314, doi: $10.1038 /$ nature 07369 .

[4] a) B. G. Reed-Berendt, K. Polidano, L. C. Morril Org. Biomol. Chem. 2019, 17, 1595, doi: 10.1039/C8OB01895B; b) A. Corma, J. Navas, M. J. Sabater, Chem. Rev. 2018, 118, 1410, doi: 10.1021/acs.chemrev.7b00340 c) K. O. Marichev, J. M. Takacs, ACS Catal. 2016, 6, 2205, doi: 10.1021/ acscatal.6b00175.

[5] A. F. Abdel-Magid, K. G. Carson, B. D. Harris, C. A. Maryanoff, R. D. Shah, J. Org. Chem. 1996, 61, 3849, doi: 10.1021/jo960057x.

[6] a) D. C. Blakemore, L. Castro, I. Churcher, D. C. Rees, A. W. Thomas, D. M. Wilson, A. Wood, Nature Chem. 2018, 10, 383, doi: 10.1038/s41557-0180021-z; b) T. Cernak, K. D. Dykstra, S. Tyagarajan, P. Vachal, S. W. Krska, Chem. Soc. Rev. 2016, 45, 546, doi: $10.1039 / \mathrm{c} 5 \mathrm{cs} 00628 \mathrm{~g}$.

[7] R. F. Borch, M. D. Bernstein, H. D. Durst, J. Am. Chem. Soc. 1971, 93, 2897, doi: 10.1021/ja00741a013.

[8] D. J. van As, T. U. Connell, M. Brzozowski, A. D. Scully, A. Polyzos, Org. Lett. 2018, 20, 905, doi: 10.1021/acs.orglett.7b03565.

[9] a) L. R. E. Pantaine, J. A. Milligan, J. K. Matsui, C. B. Kelly, G. A. Molander, Org. Lett. 2019, 21, 2317, doi: 10.1021/acs.orglett.9b00602; b) R. Wang, M. Ma, X. Gong, G. B. Panetti, X. Fan, P. J. Walsh, Org. Lett. 2018, 20, 2433 , doi: 10.1021/acs.orglett.8b00778; c) R. Wang., M. Ma, X. Gong, X. Fan, P. J. Walsh, Org. Lett. 2019, 21, 27, doi: 10.1021/acs.orglett.8b03394; d) X. Fan, X. Gong, M. Ma, R. Wang, P. J. Walsh, Nature Commun. 2018, 9; e) Z. W. Xi, L. Yang, D. Y. Wang, C. D. Pu, Y. M. Shen, C. D. Wu, X. G. Peng, J. Org. Chem. 2018, 83, 11886, doi: 10.1021/acs.joc.8b01651; f) M. Nakajima, E. Fava, S. Loescher, Z. Jiang, M. Rueping, Angew. Chem., Int. Ed. 2015, 54, 8828, doi: 10.1002/anie.201501556. g) A. L. Fuentes de Arriba, F. Urbitsch, D. J. Dixon, Chem. Commun. 2016, 52, 14434, doi: 10.1039/c6cc09172e; h) T. Rossolini, J. A. Leitch, R. Grainger, D. J. Dixon, Org. Lett. 2018, 20, 6794, doi: 10.1021/acs.orglett.8b02923; i) J. Rong, P. H. Seeberger, K. Gilmore, Org. Lett. 2018, 20, 4081, doi: 10.1021/acs.orglett.8b01637; j) M. Hager, D. W. C. MacMillan, J. Am. Chem. Soc. 2014, 136, 16986, doi: 10.1021/ ja5102695; k) L. Qi, Y. Chen, Angew. Chem., Int. Ed. 2016, 55, 13312, doi: 10.1002/anie.201607813.

[10] a) Y. Su, N. J. W. Straathof, V. Hessel, T. Noel, Chem. Eur. J. 2014, 20, 10562, doi: 10.1002/chem.201400283; b) Z. J. Garlets, J. D. Nguyen, C. R. J. Stephenson, Isr. J. Chem. 2014, 54, 351, doi: 10.1002/ijch. 201300136.

[11] a) F. Lima, M. A. Kabeshov, D. N. Tran, C. Battilocchio, J. Sedelmeier, G. Sedelmeier, B. Schenkel, S. V. Ley, Angew. Chem. Int. Ed. 2016, 55, 14085, doi: 10.1002/anie.201605548; b) F. Lima, L. Grunenberg, H. B. A. Rahman, R. Labes, J. Sedelmeier, S. V. Ley, Chem. Commun. 2018, 54, 5606, doi: 10.1039/c8cc02169d; c) L. D. Elliot, J. P. Knowles, P. J. Koovits, K. G. Maskill, M. J. Ralph, G. Lejeune, L. J. Edwards, R. I. Robinson, I. R. Clemens, B. Cox, D. D. Pascoe, G. Koch, M. Eberle, M. B. Berry, K. I. BookerMilburn, Chem. Eur. J. 2014, 20, 15226, doi: 10.1002/chem.201404347; d) J. W. Tucker, Y. Zhang, T. F. Jamison, C. R. J. Stephenson, Angew. Chem., Int. Ed. 2012, 51, 4144, doi: 10.1002/anie.201200961; e) K. C. Harper, E. G. Moschetta, S. V. Bordawekar, S. J. Wittenberger, ACS Cent. Sci. 2019, 5 , 109, doi: 10.1021/acscentsci.8b00728.

[12] a) J. W. Beatty, J. J. Douglas, R. Miller, R. C. McAtee, K. P. Cole, C. R. J. Stephenson, Chem. 2016, 1, 456, doi 10.1016/j.chempr.2016.08.002; b) D. Cambie, C. Bottecchia, N. J. W. Straathof, V. Hessel, T. Noël, Chem. Rev. 2016, 116, 10276, doi: 10.1021/acs.chemrev.5b00707.

[13] a) D. Musio, E. Gala, S. V. Ley, ACS Sustainable Chem. Eng. 2018, 6 , 1489, doi: 10.1021/acssuschemeng.7b04012 b) D. E. Fitzpatrick S.V. Ley, Tetrahedron 2018, 74, 3087, doi: 10.1016/j.tet.2017.08.050

[14] See supplementary information for cyclic voltammetry data of all imine substrates.

[15] D. Q. Wu, Z. Y. Guan, Y. Peng, J. Sun, C. Zhong, Q. H. Deng, Adv. Synth. Catal. 2018, 360, 4720, doi: 10.1002/adsc.201800810. 